\title{
Excretion of the Glucuronide of Thyroxine in Cat Bile
}

\author{
BY N. B. MYANT \\ External Staff of the Medical Research Council, Hammersmith Hospital, London, W. 12
}

(Received 11 October 1965)

\begin{abstract}
1. After intravenous injections of radioactive thyroxine into cats, about half the radioactivity excreted in the bile was in a glucuronide fraction, which, after hydrolysis with $\beta$-glucuronidase, gave rise to radioactive thyroxine and a radioactive substance that ran with $3,3^{\prime}, 5^{\prime}$-tri-iodothyronine on paper chromatography in two dimensions. 2. The proportion of the total radioactivity in the bile in the glucuronide fraction was unaffected by an intravenous injection of $750 \mu \mathrm{g}$. of nonradioactive thyroxine. 3. It is concluded that the capacity of the liver for forming the glucuronides of thyroxine and its metabolites is at least as great in cats as in monkeys. 4. These findings are discussed in relation to the question whether the liver contains one or more than one UDP-glucuronic acid glucuronyltransferase.
\end{abstract}

The liver forms glucuronides from UDP-glucuronic acid and a wide variety of acceptors, including bilirubin, steroid hormones, thyroxine and many foreign phenols such as 0 -aminophenol (see Isselbacher \& Axelrod, 1955; Dutton, 1956). UDP-glucuronic acid glucuronyltransferase (UDP. glucuronyltransferase) has been demonstrated in the livers of several species of laboratory animals and in human liver. However, doubt has been expressed whether the enzyme is present in the liver of cats (Robinson \& Williams, 1958). Dutton \& Greig (1957) were unable to demonstrate glucuronide synthesis from (-)-menthol in slices or homogenates of cat liver, although UDP-glucuronic acid was present, and Brodie \& Maickel (1961) found a lack of UDP-glucuronyltransferase in cat-liver microsomes when several other phenolic substances were used as substrates. Robinson \& Williams (1958) also failed to find glucuronides in the urine of cats given substances known to be excreted as glucuronides in the urine of rabbits. On the other hand, progesterone (Taylor \& Scratcherd, 1961) and corticosterone (Taylor, 1965) are both excreted as glucuronides in cat bile. This apparent discrepancy raises the question whether cats excrete thyroxine glucuronide in their bile.

In this paper, experiments in vivo are described which show that thyroxine is excreted mainly as glucuronides in the bile of cats, and that the maximal capacity for converting thyroxine into glucuronides is at least as great in cats as in monkeys.

\section{METHODS}

Observations were made on two cats. Cat 1, a female, weighed $2 \cdot 7 \mathrm{~kg}$; cat 2 , a male, weighed $3 \cdot 0 \mathrm{~kg}$. Anaesthesia was induced by an intraperitoneal injection of Nembutal
(30 mg./kg.), and $100 \mu \mathrm{C}$ of L-[3'-131I]thyroxine (specific activity $20-30 \mu \mathrm{c} / \mu \mathrm{g}$.) dissolved in $1 \mathrm{ml}$. of $0.9 \% \mathrm{NaCl}$ was injected into the femoral vein. Throughout the remainder of the experiment, anaesthesia was maintained by hourly intravenous injections of Nembutal $(10 \mathrm{mg} . / \mathrm{kg}$.$) , each in$ about $3 \mathrm{ml}$. of $0.9 \% \mathrm{NaCl}$. At $2 \mathrm{hr}$. after the injection of radioactive thyroxine, the gall bladder and bile ducts were exposed through a midline incision in the abdomen and the cystic duct was ligated. The common bile duct was cannulated with a polythene cannula and the peritoneum, muscles and skin of the abdominal wall were closed in separate layers. The right femoral artery and vein were exposed for taking blood samples and giving injections. The bile was collected continuously for $4-5 \mathrm{hr}$. with sampling periods of $15-25 \mathrm{~min}$. Blood samples $(0.5 \mathrm{ml}$.) were taken at half-hourly intervals from the femoral artery and the serum was separated by centrifugation. At $1 \frac{1}{2} \mathrm{hr}$. after cannulation of the bile duct each cat was given an intravenous injection of non-radioactive thyroxine dissolved in $1 \mathrm{ml}$. of $\mathrm{Na}_{2} \mathrm{CO}_{3}$ in water (pH 8-8.5). In cat 2 this was followed $1 \mathrm{hr}$. later by a second intravenous injection containing $750 \mu \mathrm{g}$. of thyroxine.

Total ${ }^{131} \mathrm{I}$ in the bile and protein-bound ${ }^{131} \mathrm{I}$ in the serum were assayed by methods described by Osorio \& Myant (1965). The biliary clearance rate of the plasma thyroxine was estimated as the product of the ratio of the concentration of ${ }^{131} \mathrm{I}$ in the bile to that of protein-bound ${ }^{131} \mathrm{I}$ in the serum (bile/serum 131I concentration ratio) and the rate of flow of bile, as described by Osorio \& Myant (1965).

Chromatography of bile. Two-dimensional chromatograms were made according to the method of Flock, Bollman, Grindlay \& Stobie (1961), with minor modifications. The sample of fresh bile $(0 \cdot 1-0 \cdot 2 \mathrm{ml}$.) was applied near

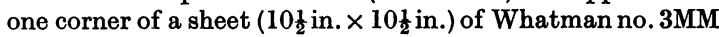
filter paper. For the first dimension butan-1-ol-dioxan $(4: 1, v / v)$ equilibrated with 5 vol. of $2 \mathrm{~N}-\mathrm{NH}_{3}$ was used as solvent; the chromatogram was developed in the ascending direction until the solvent reached the top of the paper. For the second dimension 2-methylbutan-2-ol equilibrated with $2 \mathrm{~N}-\mathrm{NH}_{3}$ was used as solvent and the chromatogram was developed in the descending direction until 5-6 hr. after the 
solvent had reached the bottom of the paper. The radioactive spots were located by radioautography. Thyroxine, 3,3',5-tri-iodothyronine, $3,3^{\prime}, 5^{\prime}$-tri-iodothyronine and $\mathrm{NaI}$ were added as markers to the bile samples before they were applied to the paper. After radioautography, the thyroxine, $3,3^{\prime}, 5$-tri-iodothyronine and $3,3^{\prime}, 5^{\prime}$-tri-iodothyronine spots were stained by spraying with diazotized sulphanilic acid (Gross \& Leblond, 1951) or with 1\% ninhydrin in butan-1-ol and the iodide spot was stained by spraying with $0.1 \%$ $\mathrm{PdCl}_{2}$ in water. The radioactive areas on the paper were cut out and assayed for radioactivity in a well-type scintillation counter.

For rapid quantitative analysis of serial samples of bile, the bile (0.1-0.2 ml.) was chromatographed in one dimension on strips of Whatman no. 3MM filter paper in the descending direction with butan-1-ol equilibrated with an equal volume of $2 \mathrm{~N}$-acetic acid as solvent. Thyroxine and NaI were added to the bile as markers. The radioactivity on the paper strips was located either by means of a continuously recording scanner or by radioautography. The proportions of the total radioactivity in each peak recorded by the scanner were determined by measuring the areas under the peaks with a planimeter.

To test for the presence of glucuronides, 500 Fishman units of Ketodase (Talalay, Fishman \& Huggins, 1946) were added to a mixture of $0.2 \mathrm{ml}$. of fresh bile and $0.2 \mathrm{ml}$. of phosphate buffer, $\mathrm{pH} 6 \cdot 5$, in a stoppered tube and shaken at $37^{\circ}$ in a water bath for $6 \mathrm{hr}$. After incubation, the mixture was centrifuged to remove sediment, and prepared for paper chromatography by evaporation to a volume of about $0.2 \mathrm{ml}$. under a stream of $\mathrm{N}_{2}$ at $50^{\circ}$.

For analysis of the glucuronide area on the two-dimensional chromatograms, the two zones were eluted separately with ethanol-2 $\mathrm{N}-\mathrm{NH}_{3}(1: 1, v / v)$ and the $\mathrm{NH}_{3}$ was removed by blowing a stream of $\mathrm{N}_{2}$ over the mixture. An equal volume of $2 \mathrm{~N}-\mathrm{HCl}$ was added and the mixture heated on a steam bath for $2 \mathrm{hr}$. The hydrolysate was evaporated to a volume of about $0.2 \mathrm{ml}$. under $\mathrm{N}_{2}$ and applied to strips of Whatman no. 3MM filter paper for chromatography with 2-methylbutan-2-ol equilibrated with $2 \mathrm{~N}-\mathrm{NH}_{3}$ as solvent, and with markers of thyroxine, 3,3',5-tri-iodothyronine, $3,3^{\prime}, 5^{\prime}$-tri-iodiothyronine and iodide. Radioautographs were made from the paper strips.

Materials. L-[3'-131I]Thyroxine was obtained from Abbott Laboratories, North Chicago, Ill., U.S.A. Ketodase was obtained from Warner-Chilcott Laboratories, Morris Plains, N.J., U.S.A. 3,3',5'-Tri-iodothyronine was a generous gift from Dr W. F. J. Cuthbertson of Glaxo Laboratories, Greenford, Middlesex. All organic solvents were of A.R. grade. Dioxan was purified by passing it through a column of alumina activated by heating for $12 \mathrm{hr}$. at $130^{\circ}$. Saccharolactone was prepared by boiling a solution of potassium hydrogen saccharate (Levvy, 1952).

\section{RESULTS}

Biliary clearance rate. In both cats the rate of flow of bile was more or less constant throughout the experiment, averaging $1.4 \mathrm{ml} . / \mathrm{hr}$. in cat 1 and $2.1 \mathrm{ml}$. $/ \mathrm{hr}$. in cat 2 . Before the injection of nonradioactive thyroxine the concentration of total 131I in the bile and of protein-bound 131I in the serum fell roughly in parallel, the bile/serum ${ }^{131}$ I

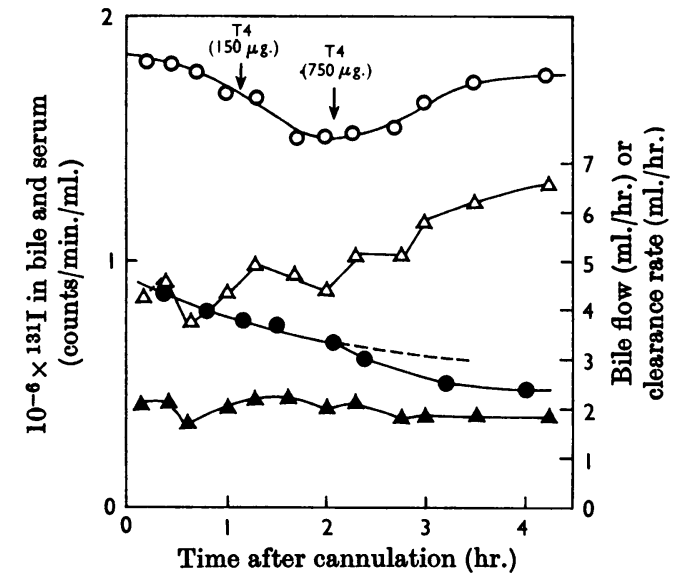

Fig. 1. Concentration of total ${ }^{131} \mathrm{I}$ in bile (O), concentration of protein-bound ${ }^{131} \mathrm{I}$ in serum $(\Theta)$, rate of flow of bile $(\Delta)$ and biliary clearance rate of plasma thyroxine $(\Delta)$ in cat 2 . Arrows show intravenous injections of thyroxine (T4).

concentration ratio averaging 1.7 in cat 1 and 2.1 in cat 2 . The biliary clearance rate of the plasma thyroxine was therefore $2.4 \mathrm{ml} . / \mathrm{hr}$. in cat 1 and $4.3 \mathrm{ml} . / \mathrm{hr}$. in cat 2 (or 0.9 and $1.4 \mathrm{ml} . / \mathrm{hr}$. $/ \mathrm{kg}$.). An intravenous injection of $150 \mu \mathrm{g}$. of thyroxine led to an increase in the bile/serum 131I concentration ratio to $12 \%$ above the resting level in cat 1 , but had no effect in cat 2. When $750 \mu \mathrm{g}$. of thyroxine was injected intravenously into cat 2 there was a fall in the concentration of protein-bound ${ }^{131} I$ in the serum to a value below that obtained by extrapolation from the pre-injection values, and a rise in the concentration of total ${ }^{131} \mathrm{I}$ in the bile; the net effect of these two changes was an increase in the biliary clearance rate to $6 \cdot 6 \mathrm{ml}$./hr. (Fig. 1).

Chromatography of bile. Two-dimensional chromatograms were made from two samples of bile from cat 1 and from five samples from cat 2. Radioautographs prepared from the chromatograms showed two main areas of radioactivity. One of these was due to thyroxine. The other (G in Fig. 2a) was in roughly the same position, in relation to thyroxine, as the glucuronide spot on chromatograms of dog bile reported by Flock et al. (1961). On chromatograms of bile from both cats, the G area contained $45-55 \%$ of the total radioactivity and usually consisted of two overlapping or (as in Fig. 2a) completely separate areas, that nearer thyroxine (G2 in Fig. 2a) being the more conspicuous of the two.

In addition to the two main areas, the radioautographs showed the presence of at least six others. One of these, containing less than $5 \%$ of the total radioactivity on the chromatogram, corresponded to the position of $3,3^{\prime}, 5$-tri-iodothyronine. 

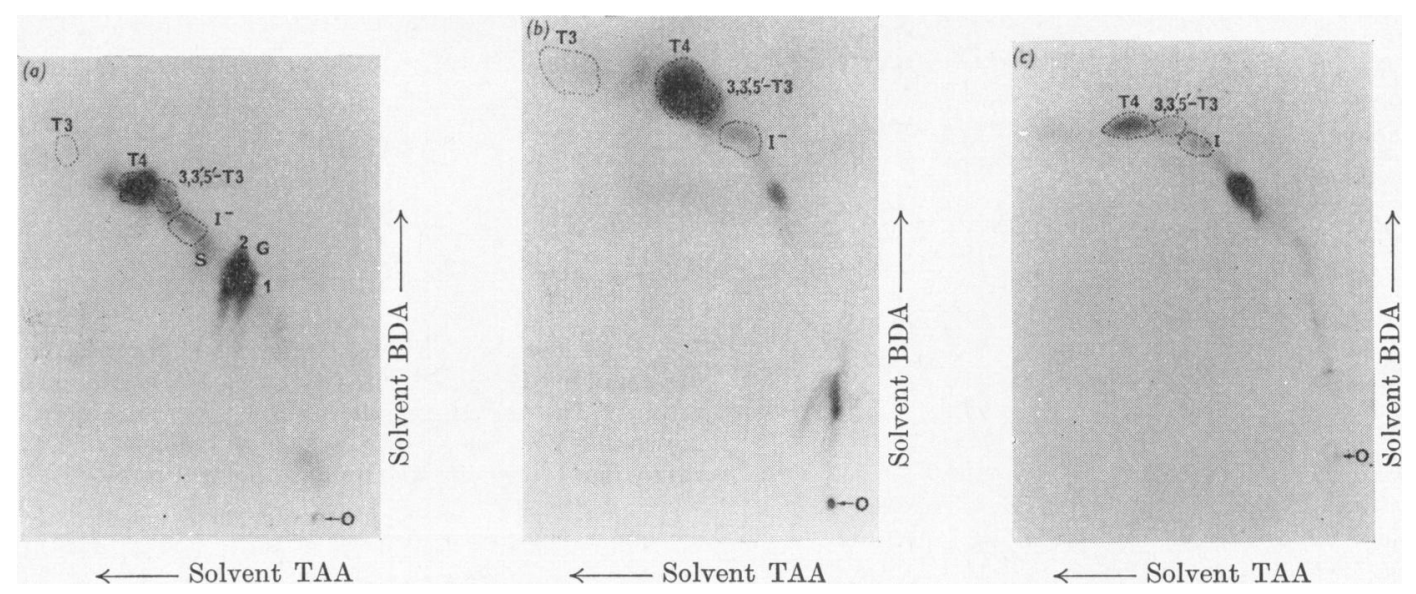

Fig. 2. Radioautographs of two-dimensional paper chromatograms of a sample of bile from cat 2 run with butan1-ol-dioxan-aq. $\mathrm{NH}_{3}$ (BDA) and 2-methylbutan-2-ol-aq. $\mathrm{NH}_{3}$ (TAA) as solvents. The broken lines show the areas occupied by the marker spots after staining. T4, Thyroxine; T3, 3,3',5-tri-iodothyronine; 3,3', $5^{\prime}-\mathbf{T}^{\prime}$, $3,3^{\prime}, 5^{\prime}$-tri-iodothyronine; $I^{-}$, iodide; $S$, spot roughly in the position of the sulphate esters of thyroid hormones; $\mathrm{G}$ (1 and 2), area in which radioactive material was hydrolysed by Ketodase. O, Origin. (a) Control sample; (b) after incubation with Ketodase; (c) after incubation with Ketodase plus saccharolactone.

Another, just behind, and overlapping with, thyroxine corresponded to the position of $3,3^{\prime}, 5^{\prime}$ tri-iodothyronine and contained $5-10 \%$ of the total radioactivity. Some radioactivity was also present as iodide. No attempt was made to identify the compounds in any of the other radioactive spots. However, the spot between thyroxine and $3,3^{\prime}, 5$ tri-iodothyronine (Fig. 2a) was in roughly the same position as tetra-iodothyronine, and another spot ( $\mathrm{S}$ in Fig. 2a), situated between the $\mathrm{G}$ area and iodide, was in roughly the position of the sulphate esters of thyroid hormones, as shown on the twodimensional chromatograms of Flock et al. (1961). On the chromatograms from cat bile, spot $S$ contained $5-10 \%$ of the total radioactivity.

When the bile was incubated with Ketodase before chromatography, the radioactivity at the $G$ area was much decreased and that due to thyroxine and to $3,3^{\prime}, 5^{\prime}$-tri-iodothyronine was increased (Fig. 2b). The effect of Ketodase was abolished by adding saccharolactone (Fig. 2c). Table 1 shows the amounts of activity in these three areas on the chromatograms shown in Fig. 2.

In an attempt to obtain more information about the radioactive substances giving rise to the two zones of blackening at the G area (Fig. 2a), the area on the chromatogram corresponding to each zone was cut out and eluted, and the eluate was submitted to paper chromatography after hydrolysis in $\mathrm{HCl}$. Almost all the activity from the spot nearer the origin (G1) ran with the $3,3^{\prime}, 5^{\prime}$-tri-iodothyronine (Fig. 3a). Most of the activity in the more conspicu-
Table 1. Effect of Ketodase and of Ketodase plus saccharolactone on radioactivity in spots due to area $G$, thyroxine and $3,3^{\prime}, 5^{\prime}$-tri-iodothyronine on the chromatograms shown in Fig. 2

Experimental details are given in the Methods section.

Percentage of total radioactivity on chromatogram

Treatment Area

None

Ketodase

Ketodase+ G Thyroxine $3,3^{\prime}, 5^{\prime}-$ saccharolactone $(0 \cdot 1 \mathrm{~mm})$

50 61 18 Tri-iodothyronine 7 15
9

ous spot (G2) ran with the thyroxine marker, but there was also a faint area of blackening on the radioautograph at the position corresponding to the $3,3^{\prime}, 5^{\prime}$-tri-iodothyronine marker (Fig. $3 b$ ).

Chromatograms of bile run in one dimension with butan-1-ol-acetic acid as solvent usually showed seven peaks of radioactivity on the record from the scanner (Fig. 4). The most conspicuous of these (peak V) moved with $R_{p} 0.56-0.59$ and was not completely separated from a small peak just behind it (peak IV). Peak V appeared to be due to more than one radioactive substance, since there was usually a secondary peak on its ascending limb (Fig. 4). Moreover, radioautographs of some of the one-dimensional chromatograms showed two overlapping 
(a)

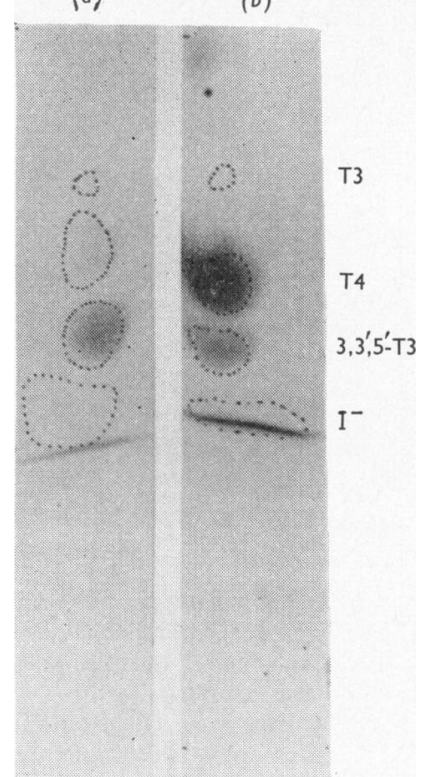

Fig. 3. Radioautographs of paper chromatograms of the hydrolysed eluates from spots G1 $(a)$ and G2 (b) (Fig. 2a) on a two-dimensional chromatogram of bile from cat 2 . The broken lines show the areas occupied by the marker spots after staining. T4, Thyroxine; T3, 3,3',5-tri-iodothyronine; $3,3^{\prime}, 5^{\prime}-\mathrm{T} 3,3,3^{\prime}, 5^{\prime}$-tri-iodothyronine; $\mathrm{I}^{-}$, iodide. 0 , Origin. The solvent was 2-methylbutan-2-ol-aq. $\mathrm{NH}_{3}$.

zones of blackening in the area corresponding to peak V.

After incubation of the bile with Ketodase, peak $V$ was almost completely abolished and the proportion of the total radioactivity in the thyroxine peak increased. When the bile was incubated with Ketodase plus saccharolactone, the proportions of the total radioactivity in peak $\mathrm{V}$ and in the thyroxine zone did not change significantly.

Effect of intravenous thyroxine on the distribution of radioactivity in bile. The time-course of excretion of glucuronides derived from thyroxine was followed by making one-dimensional chromatograms of all bile samples obtained from both cats, on the assumption that peak $\mathrm{V}$ contained all the radioactive glucuronides. The proportion of the total radioactivity excreted as glucuronide remained roughly constant throughout the experiment in both cats, before and after intravenous injections of non-radioactive thyroxine; the proportion of the total radioactivity in peak IV was also unaffected by injections of thyroxine. This was particularly striking in cat 2 , in which an injection of $750 \mu \mathrm{g}$. of thyroxine failed to have any significant effect on the distribution of radioactivity in peaks IV and V

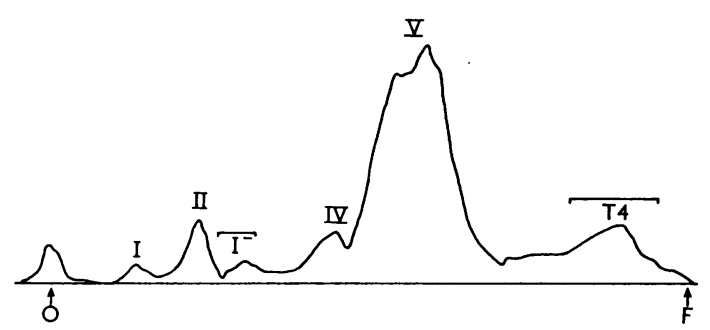

Fig. 4. Distribution of radioactivity along paper chromatogram of bile from cat 1 run with butan-1-ol-acetic acid as solvent. The positions of the marker spots are shown by horizontal lines above the peaks of radioactivity (T4, thyroxine; $\mathrm{I}^{-}$, iodide). $\mathrm{O}$, Origin, $\mathrm{F}$, solvent front.

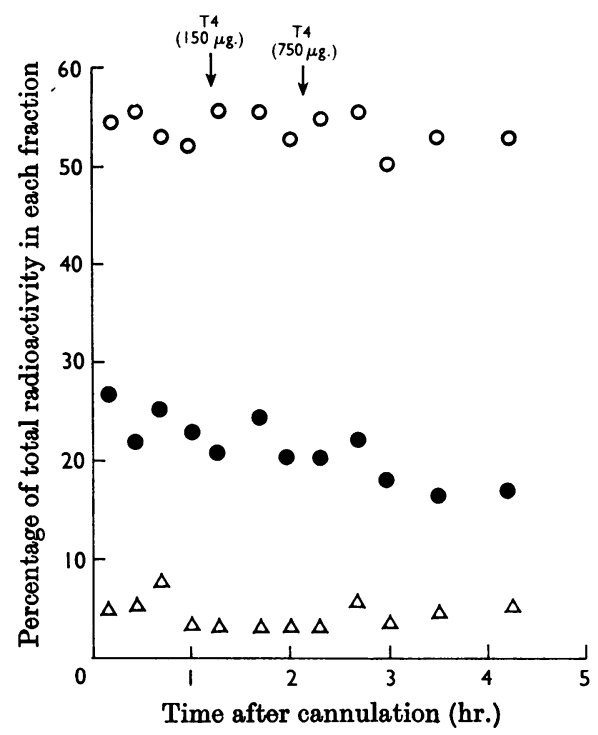

Fig. 5. Effect of intravenous thyroxine on the distribution of radioactivity in peaks IV $(\Delta), \mathrm{V}(0)$ and T4 (๑) (Fig. 4) on chromatograms of bile from cat 2 run with butan-1-olacetic acid as solvent. Arrows show intravenous injections of thyroxine (T4).

(Fig. 5), although there was a marked increase in the concentration of total 131I in the bile (Fig. 1).

\section{DISCUSSION}

The main area of blackening between thyroxine and the origin ( $\mathrm{G}$ in Fig. $2 a$ ) corresponds roughly to the position of the glucuronide spot found in bile by Flock et al. (1961), although, owing to minor differences in method, the mobility of all the radioactive spots in the second dimension was greater in this work than in the work of Flock et al. (1961) (see their Fig. 1). The almost complete disappear- 
ance of radioactivity from this area after hydrolysis with Ketodase, but not with Ketodase plus saccharolactone, provides further evidence that the major fraction of the radioactivity in cat bile was in the form of $\beta$-glucuronides, since Levvy (1952) has shown that saccharolactone inhibits $\beta$-glucuronidase. Flock et al. (1961) have shown that, when radioactive thyroxine is injected into dogs, about $40 \%$ of the radioactivity excreted in the bile is in a glucuronide fraction consisting mainly of the glucuronides of thyroxine and $3,3^{\prime}, 5^{\prime}$-tri-iodothyronine. The release of radioactive thyroxine and $3,3^{\prime}, 5^{\prime}$-tri-iodothyronine from the radioactive substances in the glucuronide area after hydrolysis with Ketodase (Fig. $2 b$ and Table 1 ) shows that cats also form these two glucuronides from thyroxine. Possibly, the two incompletely separated areas seen on the radioautographs from unhydrolysed bile (G in Fig. 2a) are due to partial separation of the glucuronides of thyroxine and $3,3^{\prime}, 5^{\prime}$-tri-iodothyronine during chromatography in the second dimension.

The radioactive substances responsible for peak V, the most prominent peak on the one-dimensional chromatograms, were almost completely hydrolysed by Ketodase but not by Ketodase in the presence of saccharolactone. This provides confirmatory evidence that in cats the plasma thyroxine is excreted in the bile mainly in the form of glucuronides. The presence of a single peak in the thyroxine region after hydrolysis with Ketodase (Fig. 4) is consistent with the presence of more than one radioactive glucuronide in the peak $\mathrm{V}$ region, since thyroxine, $3,3^{\prime}, 5$-tri-iodothyronine and $3,3^{\prime}, 5^{\prime}$-tri-iodothyronine run with the same $R_{F}$ on paper chromatograms developed with butan-1-ol-acetic acid. The distribution of radioactivity on the one-dimensional chromatograms resembled that on chromatograms of the bile of rats injected with radioactive thyroxine, in which peak $\mathrm{V}$ is much the most prominent (Cuarón, Myant \& Osorio, 1962). The distribution differs, however, from that on chromatograms of monkey bile, in which peak IV, due probably to sulphate esters, may be almost as conspicuous as peak V (Osorio \& Myant, 1965).

Some idea of the quantitative importance of the excretion of thyroxine glucuronide in cats can be gained from the observations on biliary clearance rates. In adult rats, the biliary clearance rate of the plasma thyroxine under physiological conditions is about $2 \mathrm{ml}$./hr., or $6 \mathrm{ml}$./hr./kg. body wt. (Myant, 1957), the thyroxine being excreted in the bile mainly in the glucuronide fraction (Taurog, Briggs \& Chaikoff, 1952). The observations reported here show that the biliary clearance rate in cats is not as high as in rats, but that it is at least as high as in monkeys, in which the rate is about $1.0 \mathrm{ml}$./ hr./kg. (Osorio \& Myant, 1965). An intravenous injection of $750 \mu \mathrm{g}$. of thyroxine into a $3 \mathrm{~kg}$. cat would raise the plasma thyroxine concentration to at least 40 times the physiological concentration. Yet this did not diminish the proportion of the total radioactivity in the bile present as glucuronide, nor did it diminish the biliary clearance rate of the plasma thyroxine. This suggests that the enzyme system in the cat's liver which catalyses the conversion of thyroxine into glucuronides does not approach saturation at these high concentrations of circulating thyroxine.

The excretion of thyroxine glucuronide in cat bile provides indirect evidence that cat liver contains a UDP-glucuronyltransferase catalysing the formation of thyroxine glucuronide from UDP-glucuronic acid. The evidence as to whether or not there is a single glucuronyltransferase in the liver which catalyses the formation of all glucuronides remains contradictory. In rats of the Gunn strain, which in the homozygous state are unable to form bilirubin glucuronide (Schmid, Axelrod, Hammaker \& Swarm, 1958; Lathe \& Walker, 1958) and so remain jaundiced throughout life, there is also defective formation of the glucuronide of 0 -aminophenol (Carbone \& Grodsky, 1957) and of thyroxine (Flock \& Bollman, 1959) in the liver. This suggests that all three glucuronides are formed by the same enzyme system. Against this, however, Cuarón et al. (1962) were unable to demonstrate any inhibitory effect on the formation of thyroxine glucuronide in vivo of injections of bilirubin in doses close to the maximal capacity of the rat for excreting bilirubin glucuronide in the bile. Cats have been shown to form the glucuronides of bilirubin (Lathe \& Walker, 1958) and of steroid hormones (Taylor \& Scratcherd, 1961), and the present work provides evidence that cats also form glucuronides from thyroxine. This is consistent with the possibility that cat liver contains a single enzyme system catalysing the formation of glucuronides from all three acceptors. However, the failure of cat liver to conjugate various foreign phenols (Dutton \& Greig, 1957; Brodie \& Maickel, 1961) is difficult to reconcile with the view that there is only one UDP-glucuronyltransferase in liver. The possibility that there is more than one enzyme is also suggested by the finding of Storey (1964) that in mouse-liver homogenates there is no competitive inhibition between $o$-aminophenol and $p$-nitrophenol for glucuronide formation, and by that of Van Leusden, Bakkeren, Zilliken \& Stolte (1962) that the livers of Gunn rats have a normal capacity for forming the glucuronide of $p$-nitrophenol. Perhaps the most reasonable conclusion to draw from the evidence available at present is that the liver contains several distinct glucuronyltransferases, though the deficiency of more than one transferase in rats of the Gunn strain remains to be explained. 


\section{REFERENCES}

Brodie, B. B. \& Maickel, R. P. (1961). Proc. 1st int. pharmacol. Meet., Stockholm, vol. 6, p. 299. Ed. by Brodie, B. B. \& Erdös, E. G. Oxford: Pergamon Press Ltd.

Carbone, J. V. \& Grodsky, G. M. (1957). Proc. Soc. exp. Biol., N.Y., 94, 461.

Cuarón, A., Myant, N. B. \& Osorio, C. (1962). J. Physiol. 163,160

Dutton, G. J. (1956). Biochem. J. 64, 693.

Dutton, G. J. \& Greig, C. G. (1957). Biochem. J. 66, 52 P.

Flock, E. V. \& Bollman, J. L. (1959). Fed. Proc. 18, 227.

Flock, E. V., Bollman, J. L., Grindlay, J. H. \& Stobie, G. H. (1961). Endrocrinology, 69, 626.

Gross, J. \& Leblond, C. P. (1951). Endocrinology, 48, 714. Isselbacher, K. J. \& Axelrod, J. (1955). J. Amer. chem. Soc. 77, 1070.
Lathe, G. H. \& Walker, M. (1958). Biochem. J. 70, 705.

Lovvy, G. A. (1952). Biochem.J. 52, 464.

Myant, N. B. (1957). J. Physiol. 135, 426.

Osorio, C. \& Myant, N. B. (1965). Endocrinology, 76, 938.

Robinson, D. \& Williams, R. T. (1958). Biochem.J. 68, 23 P.

Schmid, R., Axelrod, J., Hammaker, L. \& Swarm, R. L. (1958). J. clin. Invest. 37, 1123.

Storey, I. D. E. (1964). Biochem. J. 90, 16 P.

Talalay, P., Fishman, W. H. \& Huggins, C. (1946). J. biol. Chem. 166, 757.

Taurog, A., Briggs, F. N. \& Chaikoff, I. L. (1952). J. biol. Chem. 194, 655.

Taylor, W. (1965). In The Biliary System, A Symposium of the NATO Advanced Study Institute, pp. 399-418. Ed. by Taylor, W. Oxford: Blackwell Scientific Publications.

Taylor, W. \& Scratcherd, T. (1961). Biochem. J. 81, 398.

Van Leusden, H. A. I. M., Bakkeren, J. A. J. M., Zilliken, F. \& Stolte, L. A. M. (1962). Biochem. biophys. Res. Commun. 7, 67. 